\title{
FINANCIAMENTO DA EDUCAÇÃO NO BRASIL: UM BALANÇO DO GOVERNO FHC (1995-2002)
}

\author{
José Marcelino de Rezende Pinto*
}

\begin{abstract}
RESUMO: $\mathrm{O}$ artigo busca fazer uma análise das principais medidas tomadas no Governo de Fernando Henrique Cardoso com reflexos no financiamento da educação. Constata-se que, no período, aproveitando-se da hegemonia obtida no Congresso pela coalizão de centro-direita por ele articulada, foram aprovadas várias leis com forte impacto no financiamento da educação, tais como a LDB (Lei de Diretrizes e Bases da Educação Nacional), o Fundef (Fundo de Manutenção e Desenvolvimento do Ensino Fundamental e de Valorização do Magistério) e o Plano Nacional de Educação. Entende-se que a diretriz mestra adotada por este governo para o setor foi a de que os recursos já existentes são suficientes, cabendo apenas otimizar a sua utilização. Conclui-se afirmando que este governo será lembrado como aquele que gastou $4 \%$ do PIB com ensino e $8 \%$ do PIB com juros e encargos da dívida pública.
\end{abstract}

Palavras-chave: Financiamento da educação. Fundef. Plano Nacional de Educação. Governo Fernando Henrique Cardoso. Qualidade do ensino.

\section{Education Financing in Brazil: an assessment of the Fernando Henrique Cardoso's administration (1995-2002)}

ABSTRACT: This paper seeks to analyze the main education financing measures adopted by the Fernando Henrique Cardoso's administration. Between 1995 and 2002, thanks to the center-right coalition that gave the government a majority in Congress, several new laws with strong impact on education financing were approved, such as the LDB (Brazilian Education Basic Tenets Law), Fundef (Fund for the Maintenance and Development of Elementary Education and Enhancement of the Teaching Profession), and the Brazilian Education Plan. This administration has always assumed that the existing funds are

Professor da Faculdade de Filosofia, Ciências e Letras de Ribeirão Preto, da Universidade de São Paulo (USP). E-mail: jmrpinto@ffclrp.usp.br 
sufficient although their use should be optimized. In conclusion, the article states that this administration will be remembered as one that spent $4 \%$ of the GDP in education and $8 \%$ of the GDP in interests and service of the public debt.

Key words: Education financing. Fundef. Brazilian Education Plan. Fernando Henrique Cardoso's administration. Education quality.

alvez em poucas áreas como a da educação o governo de Fernando Henrique Cardoso deixará uma marca política tão forte. Tendo à frente do MEC (Ministério da Educação), nos dois mandatos, um mesmo ministro, o economista e ex-reitor da UNiCAmP Paulo Renato Souza, com passagem pelo BID (Banco Interamericano de Desenvolvimento), onde ocupou uma vicepresidência. Seu amplo prestígio junto ao presidente da República, entre as agências internacionais e com generoso, além de pouco crítico, espaço na mídia, possibilitou ao governo influenciar decisivamente na aprovação de vários instrumentos legais que regem hoje a estrutura e organização do sistema educacional brasileiro. A título de exemplo e com forte impacto no financiamento da educação, basta citar que, neste período, foram aprovadas a Lei de Diretrizes e Bases da Educação Nacional (Lei no 9.394/1996), a Emenda Constitucional no 14 que, entre outras medidas, criou o Fundo de Manutenção e Desenvolvimento do Ensino Fundamental e de Valorização do Magistério (FUNDEF) e sua regulamentação (Lei no 9.424/1996), e o Plano Nacional de Educação (Lei no 10.172/ 2001). No curto espaço deste artigo não faremos um estudo pormenorizado dessa legislação, o que já foi feito por vários autores (ver, entre outros, Saviani, 1997; Monlevade e Ferreira, 1997; Melchior, 1997; Davies, 1998; Dourado, 1999; Pinto, 2000; Oliveira e Adrião, 2001), mas procuraremos salientar seus elementos mais marcantes e seu impacto concreto nas políticas de financiamento da educação, em particular no que se refere a dotar o país com recursos que assegurem um ensino público de qualidade nas suas diferentes regiōes.

Antes, contudo, de entrar propriamente na análise das políticas gestadas no Governo FHC, importa ressaltar os principais pontos em discussão na pauta educacional no final do governo que lhe antecede (gestão Itamar Franco). De um lado, depois de idas e vindas, entrava 
no Senado o projeto da Lei de Diretrizes e Bases da Educação Nacional, que estava em discussão desde fins de 1998 e que foi finalmente aprovado pela Câmara dos Deputados em 13 de maio de 1993, projeto este (em sua versão final consolidado no substitutivo do deputado Jorge Hage) que foi fruto de ampla discussão e razoável participação popular e que, em linhas gerais, conseguia representar os interesses daqueles segmentos compromissados com a construção de uma escola pública de qualidade, articulados em torno do Fórum Nacional em Defesa da Escola Pública. Esse projeto foi incorporado, em seus principais elementos, pelo substitutivo elaborado pelo seu relator na casa, o senador Cid Sabóia, aprovado pela Comissão de Educação do Senado em 30 de novembro de 1994 e encaminhado ao plenário ainda em dezembro desse ano.

Digna de nota também foi a participação do Brasil, em março de 1990, na "Conferência de Educação para Todos", em Jomtien, na Tailândia, que resultou na assinatura da Declaração Mundial sobre Educação para Todos. Essa conferência, que teve como co-patrocinador, além da UNESCO e do UNICEF, o Banco Mundial, vai inaugurar a política, patrocinada por esse banco, de priorização sistemática do ensino fundamental, em detrimento dos demais níveis de ensino, e de defesa da relativização do dever do Estado com a educação, tendo por base o postulado de que a tarefa de assegurar a educação é de todos os setores da sociedade. Não obstante, esse evento acabou por ter reflexos interessantes no Brasil em função da mobilização das entidades ligadas à educação naquele momento. Como se sabe, essa declaração estabelecia como meta principal a universalização, nos países signatários, do acesso à educação básica a todas as crianças, jovens e adultos, assegurandose a eqüidade na distribuição dos recursos e um padrão mínimo de qualidade (Brasil, 1994). Para que estes objetivos fossem atingidos deveriam ser elaborados, pelos mesmos países, planos decenais de educação. Como desdobramento desse processo e visando a dar subsídios ao plano decenal, foi realizada em Brasília, de 10 a 14 de maio de 1993, a "Semana Nacional de Educação para Todos" com intensa participação de órgãos governamentais das três esferas de governo, assim como de entidades da sociedade civil. Desse evento resultou o "Compromisso Nacional de Educação para Todos" com o objetivo de orientar a elaboração do "Plano Decenal de Educação para Todos". Esse compromisso foi assinado, entre outros, pelo então ministro da Educação, Murílio Hingel, pelo 
presidente do CONSED (Conselho de Secretários Estaduais de Educação), Walfrido Mares Guia, pela presidente da UNDIME (União dos Dirigentes Municipais de Educação), Olindina Monteiro, e pelo representante da UnEsCo no Brasil, Miguel Angel Enriquez. Entre outros compromissos de sua agenda constava o de: "2Assegurar efciente e oportuna aplicação dos recursos constitucionalmente definidos, bem como outros que se fizerem necessários [grifo nosso], nos próximos 10 anos, para garantir a conclusão do ensino fundamental para, pelo menos, $80 \%$ da população em cada sistema de ensino." (Brasil, 1994, p. 87).

Já no texto final do Plano Decenal de Educação para Todos vamos encontrar em suas "metas globais", entre outras:

- ampliar progressivamente a participação porcentual do gasto público em educação no PIB brasileiro, de modo a atingir o índice de 5,5\%

(...)

- aumentar progressivamente a remuneração do magistério público, através de plano de carreira que assegure seu compromisso com a produtividade do sistema, ganhos reais de salário e a recuperação de sua dignidade profissional e do reconhecimento público de sua função social. (Brasil, 1994, p. 42)

Tendo em vista esta última meta, foi ainda assinado em julho de 1994, no Governo Itamar Franco, o "Acordo Nacional de Valorização do Magistério da Educação Básica” que, entre outras medidas, estabelecia o compromisso de se fixar um Piso Salarial Profissional Nacional de R\$ 300 (cerca de R\$ 700 em valores atuais). Esse acordo foi posteriormente ignorado pelo Governo FHC (Monlevade, 1996, e Silva, 1996).

Com esta rápida introdução sobre o contexto educacional no final do Governo Itamar Franco, o que queremos salientar é que, não obstante a pressão dos interesses privatistas no âmbito da Lei de Diretrizes e Bases da Educação Nacional e de agências internacionais como o Banco Mundial, os movimentos sociais envolvidos na defesa da escola pública conseguiram avanços expressivos tanto na arena legislativa (aprovação na Câmara dos Deputados, com alterações, do substitutivo Jorge Hage) quanto no executivo (compromisso de gastos públicos de 5,5\% do PIB e Piso Salarial Profissional Nacional). Como 
veremos, com a vitória do candidato Fernando Henrique Cardoso, liderando uma aliança de centro-direita, esse cenário vai sofrer uma acentuada inflexão. Sobre os principais aspectos dessa mudança é que falaremos a seguir.

Começaremos pela Lei de Diretrizes e Bases da Educação Nacional (Lei no 9.394/96). A nova composição partidária, que deu uma folgada maioria nas duas casas ao governo, e uma ação incisiva do MEC provocaram uma reviravolta no processo e, por meio de uma manobra regimental no Senado, o projeto originário da Câmara e fruto de longa discussão é substituído por outro, elaborado, a toque de caixa, na "cozinha" do MEC mas com a paternidade assumida pelo senador Darcy Ribeiro. Esse projeto é aprovado em fevereiro de 1996 no plenário, de onde retorna para a Câmara, que introduz pequenas alterações e o aprova em 17 de dezembro de 1996. De lá segue para sanção presidencial e é promulgado como lei em 20 de dezembro do mesmo ano, sem qualquer veto presidencial, fato raro em nossa história e que mostra sua total sintonia com a nova aliança no poder (Saviani, 1997).

Como já dissemos, não faremos aqui uma análise exaustiva dessa lei, mas pretendemos apontar avanços, ou recuos ante a situação anterior. No que se refere ao projeto da Câmara dos Deputados (substitutivo Jorge Hage), embora o capítulo sobre financiamento seja o que sofreu menos alteraçóes, estas ocorreram e para pior. Entre outras alteraçôes ele era mais restritivo que a lei aprovada quanto à destinação de recursos públicos para escolas privadas; ao contrário desta, excluía os gastos com transporte escolar e material didático do cômputo dos gastos com manutenção e desenvolvimento do ensino para efeito de cumprimento da vinculação constitucional ao setor. $\mathrm{O}$ mesmo acontecia com a contabilização dos gastos com aposentados, assunto sobre o qual a lei aprovada "lava as mãos", à la Pôncio Pilatos, deixando a cargo dos sistemas de ensino a sua regulamentação. Ainda no capítulo do financiamento, o projeto ampliava a alíquota do salário-educação dos atuais $2,5 \%$ da folha de pagamento das empresas para 3,5\%, criava a quota municipal desta contribuição (assunto hoje enviado para a legislação estadual) e o salário-creche com alíquota de $1 \%$ sobre a mesma base de incidência do primeiro. Estas duas alterações não encampadas no projeto aprovado representariam um adicional de cerca de 0,25\% do PIB (Produto Interno Bruto) para o ensino fundamental e a educação infantil ( $\mathrm{R}$ \$ 3 bilhóes). Por outro lado, o financiamento 
de uma educação de qualidade foi mais duramente atingido por cortes ocorridos em outros artigos e capítulos. Particularmente grave foi a retirada do texto da lei do número máximo de alunos por professor que no projeto Jorge Hage (art. 32) era de 20 alunos na creche, 25 na pré-escola e nas classes de alfabetização e 35 em demais séries e níveis. $\mathrm{Na}$ redação inócua do texto final ficou: "será objetivo permanente das autoridades responsáveis alcançar relação adequada entre o número de alunos e o professor" cabendo "ao respectivo sistema de ensino, à vista das condições disponíveis e das características regionais e locais, estabelecer parâmetro para atendimento do disposto neste artigo" (art. 25 da Lei no 9.394/96). Tendo em vista que o principal elemento de custo é o gasto com salário docente e a melhor forma de baixar seu impacto no custo total é superlotar as salas de aula (as redes privadas que o digam), pode-se ter uma idéia do que representou a retirada daqueles parâmetros mínimos, constantes no Projeto Jorge Hage, para a qualidade do ensino. No mesmo sentido foram os cortes drásticos efetuados na seção referente à carreira docente. Ali constavam, entre outros aspectos, adicional noturno e para regiões de difícil acesso, periferia das grandes cidades e para o ensino nas quatro primeiras séries do ensino fundamental; jornada preferencial de 40 horas semanais, com incentivo para a dedicação exclusiva, admitindo-se, como mínimo, a jornada de 20 horas, sempre se assegurando $50 \%$ deste tempo para atividade extraclasse (art. 100 do Projeto Jorge Hage). Todas estas medidas, de forte impacto do ponto de vista do financiamento, foram para as calendas no texto final. Em resumo, a lei aprovada pouco acrescentou diante da situação anterior do financiamento, regulada pela Constituição Federal de 1988 e pela Lei no $7.348 / 85$, de autoria do senador João Calmon, que também foi o autor da Emenda Constitucional no 24/83, a qual reintroduziu o princípio da vinculação de recursos para o ensino para os três níveis de governo na Constituição Federal de 1969, outorgada pela ditadura militar. De mais positivo no texto aprovado deve-se comentar o $\$ 5^{\circ}$ do art. 68 que estabelece o repasse dos recursos constitucionais vinculados à manutenção e ao desenvolvimento do ensino, do caixa da União, dos estados, do DF e dos municípios ao órgão responsável pela educação, de dez em dez dias. Este postulado é fundamental para dar mais transparência ao uso dos recursos educacionais e, talvez, assegurar que os porcentuais mínimos de recursos destinados ao ensino definidos nas constituições federal, estaduais e leis orgânicas municipais sejam efetivamente repassados. 
Infelizmente, pouco tem sido feito pelo governo federal e pelos tribunais de contas para que a lei seja cumprida, o que talvez explique porque o volume de gastos públicos com ensino no Brasil pouco tenha se alterado com a aprovação da Lei de Diretrizes e Bases da Educação Nacional e gire em torno de 4,2-4,5\% do PIB, cerca da metade do que se gastou, em média, no segundo mandato de FHC com o pagamento de juros e encargos da dívida pública, item que, diga-se de passagem, não possui qualquer vinculação constitucional de recursos.

A fácil aprovação da LDB foi uma demonstração do grau de hegemonia do Executivo sobre o Legislativo, a qual já havia sido testada quando da votação da Emenda Constitucional $\mathrm{n}^{\mathrm{o}} 14$, de 12 de setembro de 1996, que, entre outras medidas, criou o FUNDEF (Fundo de Manunteção e Desenvolvimento do Ensino Fundamental e de Valorização do Magistério) e que teve sua regulamentação feita pela Lei $\mathrm{n}^{\circ}$ 9.424, aprovada praticamente em conjunto com a Lei de Diretrizes e Bases da Educação Nacional, em 26 de dezembro de 1996, em um grande pacote natalino. Antes de falarmos no FUNDEF, produto mais famoso dessa emenda constitucional, cabe comentar a restrição de alguns direitos promovida pela mesma emenda e com impacto evidente no financiamento. Referimo-nos às alterações promovidas na redação dos incisos I e II do art. 208 da CF, as quais retiram a obrigatoriedade do ensino fundamental para todos aqueles que a ele não tiverem acesso na idade própria, assim como o princípio da progressiva extensão da obrigatoriedade do ensino médio. Ora, ao retirar a obrigatoriedade para os alunos, por conseqüência, o Estado também acaba se desobrigando da oferta àqueles que não reivindicam a matrícula. Embora possa parecer antidemocrático obrigar alguém com mais de 20 anos, por exemplo, a freqüentar o ensino fundamental, há que se entender que esta escolarização não deve ocorrer apenas no interesse do indivíduo, mas sim da construção de uma sociedade democrática, daí a importância da obrigatoriedade. Com isso, numa penada, mais de 80 milhôes de brasileiros vêem restringido seu acesso à conclusão do ensino fundamental ou o ingresso no ensino médio. Em outras palavras, e em perfeita sintonia com os postulados defendidos pelo Banco Mundial, a universalização do ensino médio deixa de ser prioridade e aqueles milhões de jovens e adultos que não concluíram o ensino fundamental na idade certa não encontrarão grande estímulo, por parte do Estado, para fazê-lo. O estrago só não foi maior porque, no 
afã de aprovar rapidamente a LDB, os governistas não alteraram a redação do seu art. $4^{\circ}$ que reproduz o texto original da CF de 1988. Logo e concluindo, aqueles princípios que foram retirados da Constituição continuam valendo, só que agora amparados pela lei apenas.

Contudo e inegavelmente, a medida de maior impacto dessa emenda e de sua posterior regulamentação foi a criação do FUNDEF, o que ocorreu por meio de nova redação dada ao art. 60 do Ato das Disposições Constitucionais Transitórias da CF de 1988, o qual estabelecia que nos dez anos seguintes à aprovação da Constituição os poderes públicos deveriam aplicar, pelo menos, a metade dos recursos vinculados pela $\mathrm{CF}$ ao ensino na universalização do ensino fundamental e na erradicação do analfabetismo. E aqui a mudança foi profunda pois, com a nova redação, a União, que nunca cumpriu esse artigo, teve reduzida a sua responsabilidade, assim como foi retirado do texto constitucional o compromisso de erradicar o analfabetismo (cerca de 18 milhões de pessoas com 10 anos ou mais, em 2002) e de assegurar o ensino fundamental para aqueles que a ele não tiverem acesso pela via dos programas presenciais de educação de jovens e adultos. Além disso, o mecanismo de vincular o repasse de uma parcela da receita de impostos ao número de alunos matriculados no ensino fundamental regular desencadeou um processo, em ritmo raramente visto, de municipalização desse nível de ensino, em especial nas regióes mais pobres do país, de tal forma que, de um patamar histórico de $1 / 3$ das matrículas do ensino fundamental público que vigorou até 1996, a rede municipal, hoje, já possui mais alunos que a rede estadual.

Podemos dizer que o FUNDEF, em suma, foi uma resposta do Governo FHC ao não cumprido Acordo Nacional de Valorização do Magistério da Educação Básica. Só que, em lugar de um Piso Nacional de Salário de R\$300, em valores de julho de 1994, entra um provável Salário Médio de R \$ 300, em valores de dezembro de 1996. É escusado dizer que salário médio é completamente diferente de piso salarial. Outro ponto já bastante salientado pelos estudos que tratam da matéria (ver, entre outros, Arelaro, 1999, Pinto, 1999, e Rodrigues, 2001) é o não-cumprimento por parte do Governo FHC da fórmula de cálculo do valor mínimo a ser gasto por aluno, constante na Lei no 9.424/96. Com isso, calcula-se, o ensino fundamental deixou de receber cerca de 10 bilhões de reais de recursos federais desde 1998. 
Outro problema sério do FUNDEF é que ele provoca um desestímulo de investimentos, por parte dos poderes públicos, na educação infantil, na educação de jovens e adultos e mesmo no ensino médio. Aliás, ante a pressão muito grande por mais vagas neste último nível de ensino, o que muitos estados, como São Paulo, têm feito é burlar a lei, contabilizando como gasto com ensino fundamental a parcela do salário de professores referente às aulas que eles ministram no ensino médio. Porém, talvez o aspecto mais dramático da implantação do FUNDEF seja a sua contribuição para uma municipalização irresponsável do ensino fundamental e os efeitos catastróficos que advirão com a extinção desse fundo, definida pela Constituição Federal para 31 de dezembro de 2006. No afã de conseguir recursos do fundo, municípios fecham salas de aula de pré-escola, superlotando-as com alunos do ensino fundamental; crianças com pouco mais de 6 anos, que deveriam cursar a última etapa da pré-escola, são matriculadas na $1^{\text {a }}$ série do ensino fundamental. $\mathrm{Na}$ cidade de Analândia, no rico Estado de São Paulo, chegamos a presenciar uma escola municipal de ensino fundamental que foi instalada no prédio da Câmara Municipal (que lá continua a exercer suas atividades!), o qual não possuía qualquer estrutura para abrigar uma escola. Se isso ocorre em São Paulo, imagine o que se passa pelas regiōes mais pobres do país. Contudo, o mais grave ainda está por vir, com a extinção do fundo, pois os municípios ficarão com os alunos e terão que os manter apenas com seus caraminguás. Talvez a tarefa mais urgente do parlamento eleito em 2002 seja enfrentar esta questão do valor mínimo por aluno e da extinção do FUNDEF, ainda mais porque 2006 é ano eleitoral e aí tudo ficará mais difícil.

Enquanto isso, o governo federal divulga relatórios róseos sobre os efeitos do fundo (MEC, 1999), curiosamente, divulgando apenas os ganhos de receitas dos municípios, sem mostrar que estes recursos "ganhos" correspondem exatamente às quantias perdidas pelas redes estaduais, mesmo porque os recursos adicionais federais são ínfimos (menos de 3\% dos recursos do fundo). Um outro elemento do qual a propaganda oficial se vale para confundir a opinião pública evidencia-se quando afirma que o FUNDEF amplia os recursos para o ensino no país. O que o FUNDEF fez foi dar mais transparência ao transferi-los para uma conta específica, o que facilita a fiscalização, mas não impede a fraude, como a imprensa largamente tem denunciado no país. Pena que essa transferência ocorra apenas com parte dos recursos já que o fundo abrange menos de $60 \%$ dos recursos 
vinculados ao ensino e, como vimos, pela LDB, e independentemente do fundo, essa transferência deveria ser do total dos recursos.

A única forma de o FUNDEF provocar um aumento nos gastos com ensino no país seria se o governo federal fixasse um valor mínimo por aluno que de fato assegurasse um ensino de qualidade (que hoje, para começo de conversa, não poderia ser inferior a $R \$ 1.800$ ), o que implicaria um aumento significativo de sua contribuição para o fundo. Contudo, como vimos, o Executivo sequer contribui com o mínimo definido em lei $\left(\right.$ art. $6^{\circ}, \mathbb{S} 1^{\circ}$ da Lei $n^{\circ} 9.424 / 96$ que regulamenta o fundo). Para se ter uma idéia clara do descompromisso educacional do Governo FHC com o ensino fundamental, apesar do discurso em contrário, basta citar o veto do presidente ao dispositivo dessa lei (diga-se de passagem, lei por ele enviada ao Congresso), que determinava a contabilização, para efeito de recebimento dos recursos do FUNDEF, dos alunos do ensino fundamental matriculados na modalidade presencial da educação de jovens e adultos (inciso II do $\$ 1^{\circ}$ do art. $2^{\circ}$ ). Com a não-inclusão desses alunos no cálculo do fundo, o governo federal economizou alguns milhóes de reais e os estados e municípios foram desestimulados a investir nesta modalidade de ensino, uma vez que, graças ao veto do presidente, essas matrículas não implicariam em recebimento de recursos do fundo.

Por fim, cabe comentar que um dos postulados positivos estabelecidos pela Lei de Diretrizes e Bases da Educação Nacional, em seu art. 74, que define as formas de colaboração entre os poderes públicos de governo na oferta do ensino fundamental, é o de que a oferta de matrícula dos estados e municípios deve ser proporcional à sua capacidade fiscal. Ora, com o atual estágio da municipalização no país, este princípio já foi descumprido porque os municípios possuem pouco mais da metade dos recursos tributários existentes em mãos dos estados e um número maior de alunos que estes, no nível fundamental. Além disso, devem oferecer a educação infantil, com sete anos de duração ( 0 a 6 anos), ao passo que aos estados cabe manter o ensino médio, com apenas três anos de duração, em geral.

A última medida legal de impacto, no que se refere ao financiamento da educação, adotada no Governo FHC foi a aprovação do Plano Nacional de Educação, PNE (Lei no 10.172 de 9 de janeiro de 2001). Cabe a essa lei definir as metas a serem atingidas pela educação no país na década que começa com a sua aprovação, bem como os meios para que estas se realizem. Em resumo, podemos dizer que o projeto final aprovado não chegou 
a ser parcimonioso nas metas, mas o foi absolutamente nos meios para atingi-las, ainda mais com os vetos apostos pelo presidente da República. Antes, contudo, de analisarmos as principais implicaçôes dessa lei para o financiamento, cabe uma rápida descrição de sua tramitação por ser extremamente representativa de como a educação foi tratada nos anos FHC.

Inicialmente, cabe comentar que a tramitação do PNE, em muitos aspectos, foi uma reprise do que ocorreu na Lei de Diretrizes e Bases da Educação Nacional. O ponto de partida para o PNE foi dado pela própria LDB ao estabelecer, em seu art. 87, que a União, no prazo de um ano a partir da sua aprovação (20/12/97, portanto), deveria encaminhar ao Congresso Nacional o Plano Nacional de Educação, com diretrizes e metas para os dez anos seguintes, em sintonia com a nossa já conhecida "Declaração Mundial sobre Educação para Todos”. Nesse ínterim, enquanto se travavam os debates finais em torno da aprovação do texto da Lei de Diretrizes e Bases da Educação Nacional, em 31 de julho de 1996, cerca de 5 mil pessoas, de 27 estados brasileiros, reuniam-se em Belo Horizonte, no campus da UFMG (Universidade Federal de Minas Gerais), para realizar o I Congresso Nacional de Educação (CONED), o qual, em sua plenária de encerramento, estabeleceu, como uma das tarefas de seus participantes, construir de forma coletiva e democrática um Plano Nacional de Educação que buscasse, dentro do possível, "expressar a compreensão e a vontade coletiva da sociedade brasileira" (CNTE, 1996, p. 58).

Este processo resultou no Plano Nacional de Educação: proposta da sociedade brasileira, aprovada em 9 de novembro de 1998, no II CONED, realizado também em Belo Horizonte, a partir de um documento prévio discutido com associaçôes de profissionais da área, com as entidades estudantis e com associações acadêmicas e científicas. Este projeto, por sua vez, foi encampado pelo deputado federal Ivan Valente, que lhe deu entrada na Câmara dos Deputados em 10 de fevereiro de 1998 , onde se constituiu no PL no $4.155 /$ 98. Paralelamente, o governo federal construía o seu projeto, feito a partir de consultas a diferentes entidades, o qual acabou enviado ao Congresso Nacional posteriormente ao prazo determinado pela LDB, assim como um dia após a entrada do projeto do deputado Ivan Valente. Com a identificação de PL no 4.173/98 ele foi apensado ao PL no 4.155/98 em 13 de março de 1998. Coube a relatoria ao deputado Nelson Marchezan, do PSDB e com uma longa 
folha de serviços aos governos de plantão desde os tempos da ARENA, na ditadura militar. Tendo em vista a prioridade de entrada e, portanto, de discussão do projeto encabeçado pelo deputado Ivan Valente, mais uma vez e de forma análoga ao que ocorreu na discussão da LDB, a estratégia governista foi a de apresentar um substitutivo que, em sua estrutura e princípios gerais, pautou-se no PL no 4.173/98. Contudo, tendo em vista a mobilização do Fórum Nacional em Defesa da Escola Pública e de deputados comprometidos com a defesa da escola pública, associada ao efeito das audiências públicas promovidas pela Comissão de Educação da Câmara para debater a questão, o texto final do relator apresentou alguns avanços, em especial no que se refere ao financiamento da educação, avanços estes que caíram por terra em virtude dos vetos do presidente da República ao projeto aprovado pelo Congresso. É este projeto, transformado em lei que, em linhas gerais, discutiremos a seguir nos seus aspectos que dizem respeito ao financiamento da educação.

O primeiro ponto a ressaltar diz respeito à importância dessa lei, visto que ela define as metas e os objetivos da educação brasileira para a próxima década. Em consonância com este PNE, caberá aos estados e municípios elaborarem seus respectivos planos. O princípio básico que norteou a elaboração do $P N E d a$ Sociedade Brasileira (PL no 4.155/98) foi, como define a boa técnica do planejamento, em primeiro lugar, estabelecer um parâmetro básico de custo/aluno que assegurasse um ensino de qualidade como, aliás, determinam a Constituição Federal e a LDB e, a partir daí, e tendo em vista as necessidades de atendimento dos diversos níveis e das modalidades de ensino, chegar a um valor preciso dos recursos financeiros necessários de acordo com um cronograma de desembolso para o cumprimento das metas e dos objetivos definidos pelo plano. A partir deste procedimento chegou-se ao valor de $10 \%$ do PIB a ser gasto com manutenção e desenvolvimento do ensino público, por um período de 10 anos, após o qual e vencidos os atrasos acumulados, esses valores se estabilizariam no patamar de $6 \%$ do PIB. Já o procedimento adotado no projeto aprovado foi o oposto: não se estabelece um padrão básico de custo/aluno e define-se um conjunto extremamente extenso e detalhado de metas (295 no total), sem a correspondente avaliação do respectivo impacto financeiro. O aspecto positivo do texto final do relator foi a propositura de que 
os gastos públicos com educação atingissem o equivalente a $7 \%$ do PIB, ao passo que o projeto do Executivo propunha $6,5 \%$ do $\mathrm{PIB}$ com recursos públicos e privados, o que significaria, praticamente, congelar os gastos públicos atuais com ensino, que não superam $4,5 \%$ do PIB. Contudo, este ponto positivo do texto aprovado diante do projeto do Executivo foi vetado pelo presidente e nenhum valor foi fixado. Outro problema sério que permeia todo o texto aprovado do PNE é a falta de explicitação, em suas metas quantitativas, da parcela que caberia ao Poder Público cumprir. Portanto, o quadro que se avizinha é o de uma lei feita para não vingar, o que, obviamente, vai depender das forças políticas que saírem vitoriosas nas eleições de 2002 e, mais do que isso, da mobilização popular. Mesmo porque, como veremos a seguir, para conquistarmos o cumprimento das metas previstas no PNE aprovado, mesmo com todos os problemas apontados, com certeza precisaremos de recursos da ordem daqueles previstos no PNE da Sociedade Brasileira (PL no 4.155/98), ou seja, 10\% do PIB que representam, aproximadamente, $1 / 3$ dos recursos hoje arrecadados pelo Poder Público no Brasil.

A seguir apresentaremos um quadro com as metas de principal impacto para o financiamento da educação do texto final do PNE (Lei no 10.172 de 9 de janeiro de 2001), inclusive com os itens que foram vetados pelo presidente mas cujo veto pode ser derrubado pelo Congresso Nacional na nova legislatura.

\section{Quadro 1}

PNE: Metas de maior impacto financeiro

\section{EDUCAÇÃO INFANTIL (total de 26 metas)}

- Assegurar o atendimento de $30 \%$ das crianças na faixa de 0 a 3 anos e de $60 \%$ na faixa de 4 a 6 anos, em 5 anos, atingindo $50 \%$ e $80 \%$ nessas respectivas faixas etárias, em 10 anos, universalizando o atendimento na faixa de 6 anos e incorporando-a ao ensino fundamental que passaria a ter 9 anos de duração (não define a parcela que caberia ao sistema público de ensino). (meta 1)

- Em 5 anos, prédios e instalações com padrōes mínimos de infra-estrutura. (meta 4)

- Que, em 5 anos, 100\% dos professores tenham formação de nível médio (normal) e, em 10 anos, de nível superior. (meta 5)

- $\quad$ Em 3 anos, 100\% dos municípios com estrutura de supervisão da EI (pública e privada). (meta 10)

- Alimentação escolar para todas as crianças matriculadas na EI (instituições públicas e conveniadas). (meta 12)

- Adotar progressivamente o atendimento em tempo integral (não define prazo). (meta 18)

- (VETADO) Atender, no Programa de Garantia de Renda Mínima, em 3 anos, 50\% das crianças de 0 a 6 anos que se enquadram nos seus critérios, atingindo $100 \%$ em 6 anos. (meta 22) 


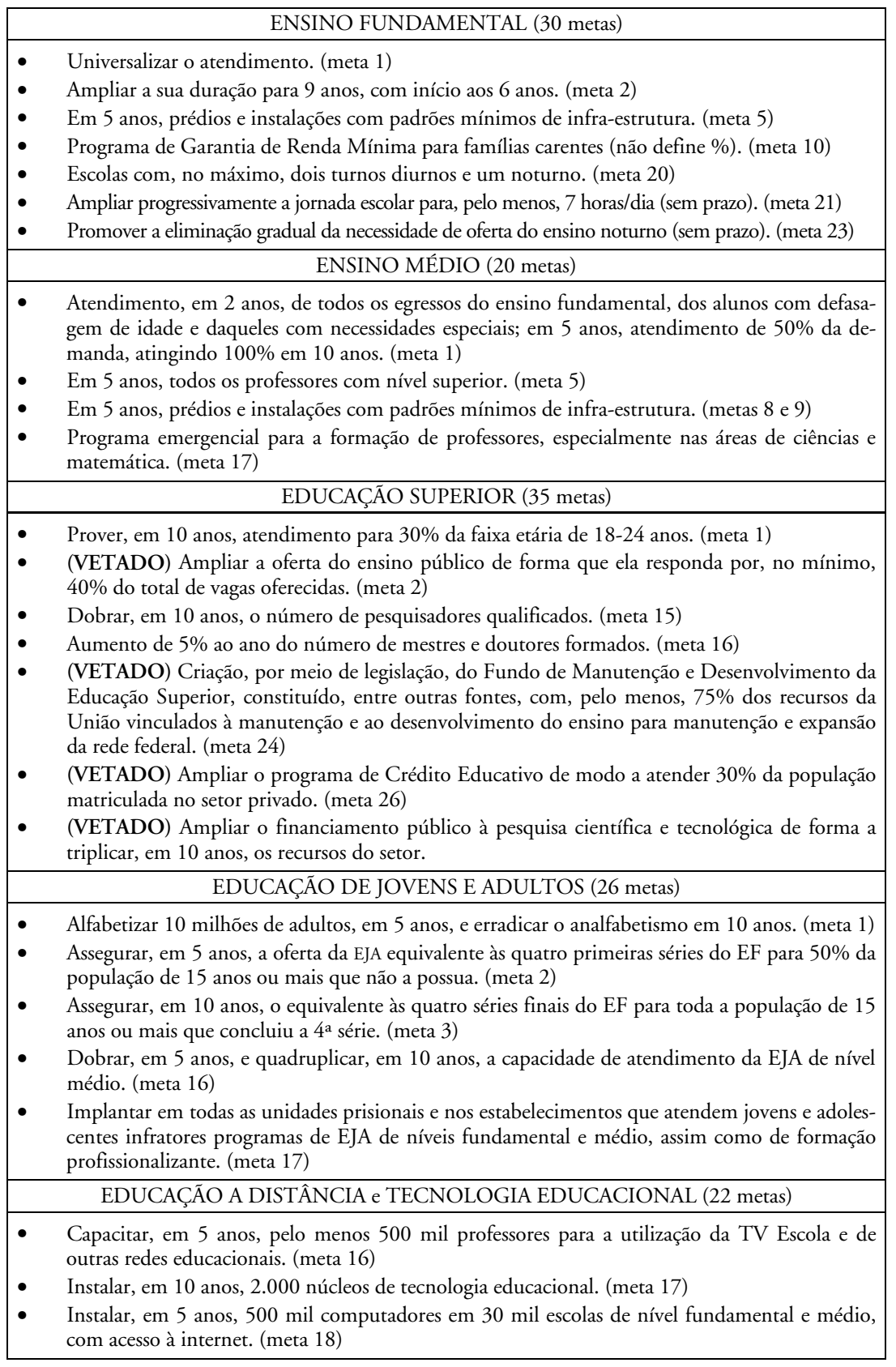

Educ. Soc., Campinas, v. 23, n. 80, setembro/2002, p. 108-135

Disponível em <http://www.cedes.unicamp.br> 
- Capacitar, em 10 anos, 120 mil professores multiplicadores em informática da educação. (meta 19)

- Capacitar, em 5 anos, 150 mil professores e 34 mil técnicos em informática educativa. (meta 20)

- Equipar, em 10 anos, com computadores e acesso à internet todas as escolas de nível médio e todas aquelas de nível fundamental que possuam mais de 100 alunos. (meta 21)

EDUCAÇÃO TECNOLÓGICA e FORMAÇÃO PROFISSIONAL (15 metas)

- Triplicar, a cada 5 anos, a oferta de cursos básicos de educação profissional. (meta 3)

- Triplicar, a cada 5 anos, a oferta de formação de nível técnico. (meta 5)

- Triplicar, a cada 5 anos, a oferta de educação profissional permanente. (meta 6)

EDUCAÇÃO ESPECIAL (28 metas)

- Generalizar, em 10 anos, o atendimento dos alunos com necessidades especiais na educação infantil e no ensino fundamental. (meta 5)

- Assegurar que, em 5 anos, todos os prédios escolares estejam adaptados com padróes mínimos de infra-estrutura para o atendimento de alunos com necessidades especiais. (meta 12)

- Aumentar os recursos financeiros destinados à educação especial de forma a atingir, em 10 anos, o mínimo de 5\% dos recursos vinculados ao ensino. (meta 23)

\section{EDUCAÇÃO INDÍGENA (21 metas)}

- Universalizar, em 10 anos, a oferta das quatro séries iniciais do EF, em uma escola indígena própria que assegure uma educação diferencial e de qualidade. (meta 3)

- Dotar, em 5 anos, as escolas indígenas com equipamento didático-pedagógico básico, incluindo biblioteca, videoteca e outros materiais de apoio. (meta 10)

- Implantar, dentro de 1 ano, cursos de educação profissional, especialmente nas regiōes agrárias, visando à auto-sustentação e ao uso da terra de forma equilibrada. (meta 19)

\section{MAGISTÉRIO DA EDUCAÇÃO BÁSICA (28 metas)}

- Garantir a implantação, já a partir do $1^{\circ}$ ano, de planos de carreira de acordo com a Lei $n^{\circ}$ 9.424/96 e com as diretrizes do Conselho Nacional de Educação. (meta 1)

- Implantar gradualmente a jornada de trabalho em tempo integral. (meta 2)

- Destinar entre 20 e $25 \%$ da carga horária dos professores para atividades extraclasse. (meta 3)

- (VETADO) Implantar, em 1 ano, planos de carreira para os profissionais de educaçáo que atuam nas áreas técnicas e administrativas e os respectivos níveis de remuneração. (meta 4)

- Generalizar, nas instituições de ensino superior públicas, cursos regulares noturnos destinados à formação de professores.

- Garantir que, em 5 anos, todos os professores da educação infantil e das quatro séries iniciais do EF, possuam, no mínimo, habilitação de nível médio na modalidade normal. (meta 17)

- Garantir que, em 10 anos, 70\% dos professores de educação infantil e EF tenham formação em nível superior, em cursos de licenciatura plena. (meta 18)

- Garantir que, em 10 anos, todos os professores do EM possuam formação em licenciatura plena nas áreas de conhecimento em que atuam. (meta 19)

FINANCIAMENTO E GESTĀO (44 metas)

- (VETADO) Elevaçáo dos gastos públicos em educaçáo até atingir 7\% do PIB, ampliando-se à razão de $0,5 \%$ do PIB nos primeiros 4 anos e $0,6 \%$ do PIB no $5^{\circ}$ ano. (meta 1 )

- Garantir, nos planos plurianuais, a previsão de suporte financeiro às metas do PNE. (meta 6)

- (VETADO) Orientar os orçamentos de modo que se cumpram as vinculaçóes e subvinculações constitucionais, e alocar, no prazo de 2 anos, em todos os níveis e modalidades de ensino, valores por aluno que correspondam a padróes mínimos de qualidade, definidos nacionalmente. (meta 7)

- (VETADO) Garantir recursos do Tesouro Nacional para o pagamento de aposentados e pensionistas do ensino público da esfera federal, excluindo-se estes gastos das despesas com manutenção e desenvolvimento do ensino. (meta 13) 
- Informatizar, em 10 anos, a administração de todas as escolas com mais de 100 alunos, conectando-as em rede com as secretarias de educação. (meta 33)

- Assegurar que, em 5 anos, $50 \%$ dos diretores possuam formação específica de nível superior, atingindo a totalidade em 10 anos. (meta 35)

Fonte: PNE (Lei no 10.172 de 9 de janeiro de 2001).

Uma rápida análise das metas apresentadas mostra com clareza a postura adotada pelo Executivo diante do projeto aprovado pelo Congresso Nacional: vetar todos os mecanismos que viabilizariam financeiramente, sem um comprometimento maior da qualidade, o atendimento das metas ali estabelecidas. Assim, de uma forma geral, foram vetados todos os itens que implicassem um aporte adicional de recursos, por parte do governo federal, como se fosse possível atender o seu conjunto de metas sem a alteração dos valores atualmente gastos com ensino no Brasil. A Tabela 1 mostra, em uma primeira aproximação, o impacto para os sistemas de ensino apenas das metas quantitativas de atendimento.

\section{Tabela 1}

Estimativa de alunos a serem atendidos com base nas metas do PNE

\begin{tabular}{|c|c|c|c|}
\hline $\begin{array}{c}\text { Nível/Modalidade de } \\
\text { Ensino }\end{array}$ & $\begin{array}{c}\text { Matrícula (2000) } \\
(\mathrm{x} 1.000)\end{array}$ & \multicolumn{2}{|c|}{$\begin{array}{c}\text { Metas do PNE (setor público e privado) } \\
\text { (alunos x 1.000) }\end{array}$} \\
\cline { 3 - 4 } & & 5 anos & 10 anos \\
\hline Creche & 917 & 2.900 & 5.000 \\
\hline Pré-escola & 4.421 & 6.000 & 8.500 \\
\hline Ensino Fundamental & 35.718 & $34.000^{* *}$ & 32.00 \\
\hline Ensino Médio & 8.193 & 12.000 & $16.000^{* * *}$ \\
\hline Ensino Superior & 2.700 & - & 7.000 \\
\hline Ed. Jovens e Adultos & 3.410 & 7.000 & 10.000 \\
\hline Alfabetização & $1.000^{*}$ & 10.000 & 18.000 \\
\hline Ed. Especial & 301 & - & 3.000 \\
\hline
\end{tabular}

Fonte: Tendo por base os dados do INEP (para matrícula) e do IBGE (para população na faixa etária), foram aplicados os índices estabelecidos pelo PNE.

* estimativa; ${ }^{* *}$ redução em função de melhoria do fluxo; ${ }^{* * *}$ maior que a população de 15-17 anos em função do atraso acumulado no atendimento e do ensino técnico.

Pelos dados da Tabela 1, constata-se o desafio que corresponde o cumprimento das metas definidas pelo PNE e o quão irresponsável foi o Executivo federal ao vetar todos os itens que apontavam para a 
ampliação, ainda que transitória, dos recursos aplicados em educação no país. Como vemos, considerando apenas o impacto no número de alunos nos próximos dez anos, estas metas implicam mais do que quintuplicar as matrículas nas creches; duplicá-las na pré-escola e no ensino médio; multiplicá-las por 2,6 vezes no ensino superior; decuplicá-las na educação especial, no ensino técnico e nos programas de alfabetização; e triplicá-las na educação de jovens e adultos. Mesmo em se considerando a ambigüidade do texto final aprovado, que não define, em boa parte das metas, a parcela de responsabilidade do setor púbico, é notório que o maior quinhão pelo seu cumprimento caberá a esse setor, mesmo porque o setor privado, no Brasil, já atingiu a parcela de mercado com condiçôes financeiras para pagar suas anuidades. No setor da educação superior inclusive, existiam, em 1999, 146 mil vagas não preenchidas (INEP), o que ajuda a entender a meta de $n^{\circ} 26$ que assegurava o crédito educativo para $30 \%$ dos alunos matriculados no setor e que, felizmente nesse caso, foi vetada pelo Executivo.

Em função destes fatos, podemos dizer com tranqüilidade que se o país quiser, de fato, cumprir as metas quantitativas e qualitativas fixadas pelo PNE, precisará destinar, ao setor educacional público, recursos equivalentes a $10 \%$ do seu PIB nos próximos dez anos. Veremos, a seguir, de que forma o arcabouço jurídico aprovado nesse período, sob influência direta do presidente e do seu ministro da Educação, refletiu-se nas políticas educacionais adotadas.

\section{A política educacional em ação}

No que se refere ao financiamento da educação, podemos dizer que a política para o setor nos anos FHC teve como pressuposto básico o postulado de que os recursos existentes para a educação no Brasil são suficientes, cabendo apenas otimizar a sua utilização, por meio de uma maior focagem nos investimentos e uma maior "participação" da sociedade. Dentro desta lógica, aliás, em fina coerência com o pensamento neoliberal, prioriza-se, por exemplo, o ensino fundamental em detrimento do ensino superior, ou ainda, no caso do primeiro, o ensino para as crianças na faixa etária ideal, em detrimento da educação de jovens e adultos. Quanto a possíveis recursos adicionais, estes deverão advir do setor privado, por intermédio das parcerias com empresas ou do trabalho voluntário de pais e dos "amigos da escola" conforme conhecido projeto da 
Rede Globo de Televisão. Esta postura talvez explique porque, no período FHC, o país gastou em recursos públicos, em média, $4 \%$ do PIB com ensino e $8 \%$ do PIB com o pagamento de juros e encargos da dívida pública. $O$ resultado foi um gasto médio por aluno da educação básica da ordem de $11 \%$ de nossa renda per capita, ou cerca de US\$300/aluno-ano. Nos EUA este valor é superior em termos absolutos (US\$7.000/aluno-ano), como seria de se esperar, mas também em termos de esforço educacional, já que este valor por aluno corresponde a cerca de $24 \%$ de sua renda per capita.

O Governo FHC também vai ser lembrado pela intensa propaganda que fez para mostrar que os gastos com educação no país foram comparáveis àqueles dos países desenvolvidos. $\mathrm{O}$ ponto alto desta batalha de marketing foi manchete estampada no boletim online do INEP de 23/11/98, que dizia: "Brasil gasta com educação igual (sic) países da OCDE". De acordo com o texto, segundo dados da OCDE (Organização para a Cooperação e o Desenvolvimento Econômico), o país gastava em educação pública o equivalente a $5 \%$ do PIB, fato que o colocava no mesmo patamar de boa parte dos países do Primeiro Mundo. Esta notícia, como boa parte daquelas divulgadas pelo INEP em seu site, teve entusiasmada repercussão por parte da imprenssa local, que sempre ressaltou como fonte da informação a insuspeita OCDE. O truque foi desmascarado por Otaviano Helene (2000) professor do Instituto de Física da USP, conforme depoimento dado em audiência pública na Câmara dos Deputados referente ao PNE. Ele entrou em contato com a OCDE, solicitando informações sobre como a organização havia chegado àquele gasto com educação para o país e obteve como resposta que a fonte fora, na verdade, o próprio INEP. Bem, contado o milagre, vamos ao santo, ou seja, qual foi a fonte do INEP? Este se valeu, na verdade, de um estudo feito pelo economista Barjas Negri, ex-presidente do FNDE (Fundo Nacional de Desenvolvimento da Educação), arquiteto do FUNDEF e que, ainda, substituiu José Serra no Ministério da Saúde. Nesse trabalho, o autor, tendo por base a receita de impostos dos diferentes níveis de governo e os porcentuais mínimos vinculados ao ensino e, somandose a isso os recursos do salário-educação e do sistema "s" (SENAI, SENAC e SENAT) e estimando-se, grosseiramente, o gasto das famílias no setor privado em $0,9 \%$ do PIB, chega-se a $5,4 \%$ do PIB em recursos públicos e privados (Negri, 1997). O INEP, em seu relatório à OCDE, transformou então este valor em 5\% do PIB em recursos públicos. 
Este cálculo consta também em um texto "para inglês ler" produzido pelo MEC, "Development of education in Brazil" (MEC, 1996). Assim, no que se refere aos recursos vinculados para o ensino, o valor a que o estudo de Negri chegou reflete o quanto o país gastaria com manutenção e desenvolvimento do ensino se a Constituição Federal, as constituições estaduais e as leis orgânicas fossem cumpridas. Ora, mas o grande problema, quando o assunto é o financiamento da educação, é exatamente que os poderes públicos tudo fazem para burlar a determinação legal; é o dilema da diferença entre os recursos potenciais para o ensino e aqueles efetivamente gastos e nesse aspecto o Governo FHC pouco fez para dar mais transparência a essa difícil questão. Nesse sentido, a Tabela 2 apresenta uma estimativa, com dados de 2000, sobre o potencial de recursos disponíveis para o ensino no Brasil.

\section{Tabela 2}

Potencial de recursos para o ensino advindo da receita de impostos (em \% do PIB) 2000

\begin{tabular}{|c|c|c|c|c|}
\hline & União & Estados* $^{*}$ & Municípios & Total \\
\hline Receita Líquida de Impostos & 4,1 & 8,2 & 4,1 & 16,4 \\
\hline Potencial para Educação & 0,74 & 2,4 & 1,03 & 4,2 \\
\hline
\end{tabular}

Fonte dos dados da receita de impostos: SNT

* Considerando 35\% para RS e RJ, 30\% para SP, MT, PI e SP e 25\% para os demais.

Considerando ainda a receita do salário-educação $(0,27 \%$ do PIB), concluímos, portanto, que o potencial de recursos para o ensino é de cerca de $4,5 \%$ do PIB, um valor, como vimos, claramente insuficiente para que sejam atingidas as metas do PNE. Por outro lado, fica a questão: quanto é gasto, de fato, com ensino no país? $\mathrm{O}$ estudo que mais buscou aproximar-se dos valores efetivamente gastos foi feito pelo IPEA (Castro e Fernandes, 1999) e chegou a um valor de $4,2 \%$ do PIB para os gastos com ensino no Brasil. Cabe, contudo, ressaltar que esse estudo tomou por base dados de 1995, antes portanto da aprovação da LDB. Todavia, como vimos, essa lei não introduziu modificaçôes significativas no que se refere à ampliação dos recursos para o ensino e, logo, há uma grande probabilidade de o número efetivamente gasto atualmente estar próximo deste apontado pelo IPEA. 
Cabe comentar, ainda, que esse trabalho do IPEA se valeu dos dados de balanço, que são infinitamente superiores aos dados de orçamento, mas que ainda trazem muita gordura embutida nos gastos com ensino. Mesmo com o advento da LDB, o descumprimento à vinculação constitucional permanece. Basta citar o caso da cidade de São Paulo, onde prefeitos como Paulo Maluf e Celso Pitta descumpriram sistematicamente a vinculação definida pela Lei Orgânica e Marta Suplicy parece ter ido mais além ao ampliar o conceito do que sejam gastos com ensino por meio da Lei Municipal no 13.245/2001, em choque, aliás, com a LDB. Estas manipulações dos gastos com ensino atingem também o Estado de São Paulo, onde, conforme relatório da CPI da Assembléia Legislativa, que teve como presidente o deputado Cesar Callegari, deixou-se de aplicar em ensino o equivalente a R \$ 6 bilhôes, de 1995 a 1998, na gestão de Mário Covas (Callegari, 2000). Segundo esta CPI até recursos destinados à alimentação para os animais do zoológico foram contabilizados como gastos com ensino. Se estes problemas acontecem na maior cidade e no maior estado do país, o que dizer sobre as regióes onde o controle social e a fiscalização são muito mais tênues.

Portanto, nos anos FHC, apesar do o país ter vivido um progressivo aumento da carga tributária, esta melhoria da arrecadação pouco repercutiu no sentido de ampliar efetivamente os gastos com ensino no Brasil. Aliás, dois fatores ajudam a entender porque esse aumento das receitas públicas não se refletiu em maiores gastos com ensino. Em primeiro lugar, isso aconteceu porque boa parte do aumento recente ocorreu na esfera federal, que é a que possui menor comprometimento com a educação, sendo responsável, segundo o mesmo estudo do IPEA (Castro e Fernandes, 1999), por apenas 25\% dos gastos do setor. Inclusive, no período, apesar do grande aumento das receitas federais, os gastos da União com ensino caíram em termos reais (Ação Educativa, 1999). Em segundo lugar, o aumento de receita ocorreu basicamente por meio da criação de fundos e contribuiçōes, como a CPMF (Contribuição "Provisória" sobre a Movimentação Financeira), que são fontes sobre as quais não incidem os porcentuais constitucionais para o ensino (que só se aplicam sobre os impostos) nem as transferências constitucionais para os estados e municípios.

Um outro aspecto das políticas concretas de financiamento da educação do Governo FHC que merece análise refere-se à forma como foram enfrentadas as desigualdades regionais no setor. E aqui a 
situação encontrada por ele, ao assumir a presidência, era preocupante; segundo ainda os dados obtidos por Castro e Fernandes (1999), em 1995 o gasto médio por aluno do ensino fundamental variou entre um mínimo de R\$ 216 no Estado do Pará e um máximo de R\$ 1.635 no Distrito Federal (que recebe recursos da União) (Castro e Fernandes, 1999). Calculando-se o desvio-padrão entre os diferentes estados, obtém-se, para um valor médio de $\mathrm{R} \$ 460$, um índice de 56\% quando se considera o valor do DF, e de $30 \%$ quando não se leva em conta esta unidade da federação. Entre as redes municipais e estaduais, nas quais se encontram 90\% dos alunos do ensino fundamental, notam-se também grandes discrepâncias. Assim, segundo o mesmo estudo, o gasto médio por aluno na rede municipal em 1995 foi de $\mathrm{R} \$ 418$, ao passo que na rede estadual foi de $\mathrm{R} \$ 502$, um valor 20\% superior. As diferenças, contudo, no interior dos estados são muito mais gritantes. Assim, enquanto o gasto médio por aluno na rede estadual de São Paulo foi de $\mathrm{R} \$ 574$, na rede municipal ele foi de $\mathrm{R} \$ 1.390$, um valor 2,4 vezes maior. Em situação oposta, nos estados de Alagoas, Maranhão e Piauí, os alunos que freqüentaram as escolas estaduais de ensino fundamental receberam, em média, 2,5 vezes mais recursos que seus colegas que freqüentaram a rede municipal.

Para enfrentar esse problema, o Executivo passou a ter, com a aprovação do FUNDEF, um grande instrumento à mão. Contudo a possibilidade de reduzir as diferenças entre estados nos gastos por aluno não se transformou em realidade porque, como já vimos, o governo federal não cumpriu o papel que lhe cabia de equalizar os gastos. Assim, segundo dados da Secretaria do Tesouro Nacional (sTN, 2000), em 1999, o fundo propiciou um valor médio de R\$ 474 por aluno/ ano, oscilando entre R\$ 308 no Estado de Pernambuco e R \$ 927 no Estado de Roraima, com um desvio-padrão de $34 \%$ em relação à media. Fosse outra a postura do governo federal, fixando, por exemplo, um valor mínimo de $\mathrm{R} \$ 1.000 /$ aluno, um grande passo teria sido dado para resolver este problema. Contudo, como já comentamos, nem o mínimo definido pela fórmula da lei (cerca de $\mathrm{R} \$ 465$ nesse ano de 1999) foi cumprido.

Por outro lado, o FUNDEF exerceu um forte impacto no sentido de reduzir as discrepâncias encontradas entre os gastos por aluno nas diferentes redes de ensino no interior de um mesmo estado. O problema é que esta equalização se deu pela via da socialização da miséria, tornando precárias aquelas redes que, em função de gastos 
mais elevados, apresentavam melhores indicadores de qualidade e salários. Por sua vez, os recursos transferidos para as redes mais pobres foram insuficientes para que estas apresentassem indicadores mínimos de qualidade como determina a Constituição Federal. Por fim, como estudo do próprio MEC (1999) e a imprensa do país mostraram, o FUNDEF não conseguiu impedir fraudes na utilização dos recursos da educação.

Um último aspecto a se comentar nesta avaliação refere-se aos empréstimos internacionais na área da educação. Tendo por base apenas aqueles firmados na esfera do Banco Mundial, constata-se que foram aprovados, na gestão FHC, cinco projetos (Fundescola 1 e 2, Projeto de Fortalecimeno da Qualidade da Educação Básica do Ceará, Projeto de Educação na Bahia e Projeto de Suporte à Reforma em Ciência e Tecnologia), totalizando US\$ 579 milhóes de recursos do banco, com a correspondente contrapartida do governo brasileiro. Existem ainda dois projetos em análise, o Fundescola 3 e o Projeto de Desenvolvimento da Infância Precoce, que totalizam US\$ 280 milhões de recursos do banco (Banco Mundial, 2002). Não é nosso objetivo fazer uma análise detalhada desses projetos, mas o que se constata é que eles estão em sintonia com a prioridade do banco de investir principalmente no ensino fundamental, particularmente nas quatro séries iniciais, e que reproduzem boa parte dos problemas detectados pelos estudos já feitos sobre eles. Entre estes salientamos: custo financeiro elevado, uma vez que são empréstimos bancários; presença de custos indiretos significativos para a elaboração dos projetos; pequena participação tanto técnica quanto social na sua elaboração e no acompanhamento dos quais, geralmente, são excluídos tanto o parlamento quanto os eventuais "beneficiários" como os executivos estaduais e municipais; captação de recursos (caros) para projetos que poderiam ser desenvolvidos com recursos locais; constrangimento das políticas educacionais mais amplas a seus objetivos e metas; e, por fim, reduzida eficácia diante dos objetivos pretendidos (Fonseca, 1995, Lauglo, 1997, e Ação Educativa, 1999). Assim, o que se constata é que o país pouco se beneficia desses recursos que, proporcionalmente, pouco representam no total de recursos aplicados em educação (menos de 1\%), mas que acabam tendo uma influência decisiva em alinhar as políticas educacionais do país com aquelas priorizadas pelas agências multilaterais (leia-se nações mais ricas do mundo), políticas estas que, diga-se de passagem, não são seguidas pelos países que controlam essas agências. 
Porém, se a educação brasileira pouco se beneficia destes empréstimos, eles fazem a alegria dos funcionários do Banco Mundial (afinal bancos só existem em função de empréstimos) e de um grupo de burocratas, encastelados no setor público e privado, que coordenam e fazem a intermediação desses projetos, e que, inclusive, podem fazer carreira nessas agências multilaterais, como ocorreu com o exministro Paulo Renato Souza. Esses projetos ajudam, inclusive, a financiar pesquisa no exterior. É o que aconteceu com o Fundescola, projeto de maior fôlego do Governo FHC, previsto para várias etapas e destinado a "melhorar o desempenho do Ensino Primário Público em áreas selecionadas das regiōes Norte, Nordeste e Centro-Oeste" (Banco Mundial, 2002). Mantendo ainda uma denominação de nível de ensino que foi abolida em 1971, o projeto envolve reforma e construção de prédios escolares, produção de material didático, financiamento do SAEB (Sistema de Avaliação da Educação Básica), formação de professores e diretores e repasse de recursos diretos para as escolas gastarem de acordo com um "plano de desenvolvimento da escola", elaborado com ampla participação de sua comunidade, segundo o texto do projeto (Banco Mundial, 2002). O interessante desse projeto é que ao passo que ele destina míseros $\mathrm{R} \$ 10$ por aluno/ano para as escolas implementarem seus planos, a Universidade de Stanford vai receber mais de US\$ 1 milhão para avaliá-lo. A escolha desta instituição se deve, provavelmente, ao fato de seus pesquisadores atuarem geralmente como consultores do Banco Mundial; sua contratação com recursos generosos seria, portanto, uma estratégia adotada pelo MEC para facilitar a aprovação da etapa 3 do projeto, na expectativa de um parecer favorável daquela instituição. Um dado de interesse é que, entre os consultores contratados, encontra-se Eric Hanushek, um pesquisador que direciona boa parte dos seus trabalhos para provar que a ampliação dos recursos educacionais (como melhores salários e redução dos alunos/classe) não altera a qualidade do ensino (Hanushek, 1996). Nos EUA, seus trabalhos sofrem séria contestação (ver Hedges e Greenwald, 1996) mas, agora, o governo brasileiro está ajudando-o a financiar suas pesquisas. Enquanto isso, no ensino fundamental e médio, os EUA possuem uma média de 16 alunos por classe e seus professores ganham, em média, US\$ $40 \mathrm{mil} /$ ano (1998) (NEA, 2000). Já o Brasil atende a cerca de 40 alunos/turma e seus professores ganham, em média, menos de US\$ 6 mil/ano (1997), para uma jornada bem mais extensa (MEC-INEP, 1998). 


\section{Conclusão}

Concluiremos este trabalho realçando os grandes desafios que o novo governante do país e sua equipe terão pela frente como herança do governo aqui analisado. E, a meu ver, eles são, basicamente, dois. O primeiro grande desafio é desativar a bomba-relógio chamada FUNDEF. Com o fim desse fundo, constitucionalmente previsto para ocorrer em 31 de dezembro de 2006, os sistemas de ensino municipais, em especial nas regiões mais pobres do país, viverão o caos em função do fim dos repasses de recursos estaduais. Esta tarefa exigirá uma grande habilidade do futuro presidente, no Congresso, pois, em especial, os governadores não terão grande interesse na prorrogação do FUNDEF, ou em sua substituição por algum outro fundo (como o FUNDEB) que implique reduzir seus recursos tributários.

O segundo grande desafio será o de criar condições para que as metas do PNE, que agora possuem força legal, sejam cumpridas. Como vimos, isso só será possível com a ampliação dos gastos públicos com educação no país. Isso porque as metas do PNE sinalizam para a necessidade de recursos da ordem de $10 \%$ do PIB, nos próximos dez anos, ao passo que o potencial atual está na casa dos 4,5\% do PIB. Este aumento vai depender de um esforço conjunto das três esferas públicas, mas com prioridade para a União, já que esta detém a maior parte dos recursos públicos no país (considerando impostos e contribuições) e é a que menos se envolve com o financiamento da educação. Uma forma também de ampliar os recursos vinculados e que não implicariam aumento da carga tributária seria a aprovação de uma emenda constitucional que determinasse que a vinculação para o ensino incidisse não apenas sobre a receita de impostos, mas que englobasse também as contribuiçôes sociais e econômicas, as quais, em 2000, representavam, só na esfera federal, o equivalente a $14 \%$ do PIB, dos quais apenas 1,9\% (salário-educação) se destinava à educação. Uma medida desta natureza, que teria pouco impacto sobre as finanças dos estados e municípios, representaria um acréscimo de recursos para a educação da ordem de $2,5 \%$ do PIB. Além desses recursos, nunca é demais ressaltar aqueles que adviriam da melhoria da eficácia do sistema arrecadador (segundo o chefe da Receita Federal, Everardo Maciel, tendo por base os dados da CPMF, o equivalente a 1 PIB escapa à tributação no país), da redução do mercado informal de trabalho e da rediscussão das isenções e dos incentivos fiscais 
que somam cerca de $2 \%$ do PIB, só na esfera federal. Uma medida a ser considerada também é o uso do déficit público para financiar a educação. Afinal, se esse déficit já foi usado para financiar tantas políticas desenvolvimentistas que pouco fizeram o país crescer e em nada alteraram a sua distribuição de renda, a pior do mundo, por que não tentar com a educação?

Por último, nunca é demais dizer que uma política efetiva de distribuição de renda, a qual, no caso do Brasil, passa obrigatoriamente por uma reforma agrária e educacional de fôlego, é um dos melhores instrumentos de promoçãa do desenvolvimento econômico, aumentando a receita pública no país e, por conseguinte, os recursos para a educação. Foi este o caminho seguido pela maioria dos países desenvolvidos, e deu certo.

Recebido e aprovado em julho de 2002.

Referências bibliográficas

AÇÃO EDUCATIVA. O impacto do FMI na educação brasileira. São Paulo: Ação Educativa, 1999. Disponível em: <www.acaoeducativa.org> Acesso em: 2002

ARELARO, L.G.R. Financiamento e qualidade da educação brasileira: algumas reflexões sobre o documento "Balanço do primeiro ano do FUndeF - Relatório MEC”. In: Dourado, L. (Org.). Financiamento da educação básica. Campinas: Autores Associados; Goiânia: Ed. da UFG, 1999.

BANCO MUNDIAL. Todos os dados referentes aos projetos foram retirados do site do banco. Disponível em: <www.worldbank.org> Acesso em: 2002.

BRASIL. Constituição da República Federativa do Brasil. São Paulo: Saraiva, 1999.

BRASIL. Emenda Constitucional n. 14/96, de 12 de setembro de 1996. Modifica os arts. 34, 208, 211 e 212 da Constituição Federal e dá nova redação ao art. 60 do Ato de disposições constitucionais transitórias. Diário Oficial da União, Brasília, DF., 13 set. 1996. 
BRASIL. Lei de Diretrizes e Bases da Educação Nacional. Lei no 9.394/96, de 20 de dezembro de 1996. Estabelece as diretrizes e bases da educação nacional. Diário Oficial da União, Brasília, DF, 23 dez. 1996.

BRASIL. Lei no 9424/96, de 24 de dezembro de1996. Dispóe sobre o Fundo de Manutenção e Desenvolvimento do Ensino Fundamental e de Valorização do Magistério. Diário Oficial da União, Brasília, DF.

BRASIL. Lei no 10.172, de 9 de janeiro de 2001. Aprova o Plano Nacional de Educação e dá outras providencias. Diário Oficial da União. Brasília, DF, 10 jan. 2001.

BRASIL. Plano Decenal de Educação para Todos 1993-2003. Brasília, DF: MEC, 1994.

BRASIL. Ministerio da Educação e do Desporto. Development of education in Brazil. Brasília, DF: MEC, 1996.

BRASIL. Ministério da Educação e do Desporto. Instituto Nacional de Pesquisas Educacionais. Censo do professor. Brasília, DF: MEC/ INEP, 1998.

BRASIL. Ministério da Educação e do Desporto. Secretaria de Ensino Fundamental.. Balanço do primeiro ano do FUNDEF. Brasília, DF: MEC/INEP, 1999.

CALLEGARI, C. Educação: uma CPI sem pizza. São Paulo, 2000. Disponível em: <www.cesarcallegari.com.br> Acesso em. maio 2002.

CASTRO, J.A.; FERNANDES, M.A.C. Sistema de informações sobre gastos públicos na área de educação - SIGPE: diagnóstico dos gastos públicos na área de educação 1995. Brasília, DF: IPEA, 1999 (versão preliminar - 11/6/99 mimeo.)

CONFEDERAÇÃO NACIONAL DOS TRABALHADORES EM EDUCAÇÃO. Plenária de encerramento do I CONED. Cadernos de Educação CNTE, Brasília, DF, v. 1, n. 2, 1996.

CONGRESSO NACIONAL DE EDUCAÇÃO, 2., 1997, Belo Horizonte. Plano Nacional de Educação: proposta do II CONED. Belo Horizonte, 1997. 
DAVIES, N. O Fundef e o orçamento da educação: desvendando a caixa-preta. São Paulo: Xamã; Rio de Janeiro: UM, 1998.

DOURADO, L. (Org.). Financiamento da educação básica. Campinas: Autores Associados; Goiânia: Ed. da UFG, 1999.

FONSECA, M. O Banco Mundial e a educação brasileira. In: OliveIra, R.P. (Org.). Política educacional: impasses e alternativas. São Paulo: Cortez, 1995.

HANUSHEK, E.A. School resources and student performance. In: Burtless, G. (Ed.). Does money matter?: the effect of school resources on student achievement and adult success. Washington, DC: The Brooking Institution, 1996.

HEDGES, L.V.; GREENWALD, R. Have times changed?: the relation between school resources and student performance. In: BURTLESS, G. (Ed.). Does money matter?: the effect of school resources on student achievement and adult success. Washington, DC: The Brooking Institution, 1996.

HELENE, O. Depoimento dado à Comissão de Educação da Câmara dos Deputados em audiência pública sobre o PNE cujo tema era o financiamento da educação. 2000 (mimeo.).

LAUGLO, J. Crítica às prioridades e estratégias do Banco Mundial para a educação. Cadernos de Pesquisa, São Paulo: Fundação Carlos Chagas, n. 100, p. 11-36, mar. 1997.

LUCE, M.B.; FARENZENA, N. Financiamento da educação infantil $e$ do ensino fundamental nos municipios do Rio Grande do Sul: estudo das fontes e usos de recursos e dos custos educacionais. Porto Alegre: UfRGS, 1998.

MARTINS, P.S. Financiamento da educação no município. In: PROGRAMA de Apoio aos Secretários Municipais de Educação PRASEM II. Brasília, DF: MEC/UniCEF/undime, 1999.

MELCHIOR, J.C.A. Mudanças no financiamento da educação no Brasil. São Paulo: Autores Associados, 1997

MONLEVADE, J.C. O financiamento da educação básica no Brasil (1549-1996). Cadernos de Educação CNTE, Brasília, v. 1, n. 2, p. 47-51, 1996. 
MONLEVADE, J.C. Educação pública no Brasil: contos \& de\$conto\$. Ceilândia: Idéa, 1997.

MONLEVADE, J.C.; FERREIRA, E.B. O FUNDEF e seus pecados capitais. Ceilândia: Idéa , 1997.

NATIONAL EDUCATION ASSOCIATION. Ranking of States: 2000. Washington, DC: NEA, [2000?]

OLIVEIRA, R.; ADRIĀO, T. (Orgs.). Gestão, financiamento e direito à educação. São Paulo: Xamã, 2001.

PINTO, J.M.R. Um fundinho chamado fundão. In: Dourado, L.F. (Org.). Financiamento da educação básica. Campinas: Autores Associados; Goiânia: Ed. da UFG, 1999.

PINTO, J.M.R. Os recursos para a educação no Brasil no contexto das finanças públicas. Brasília, DF: Plano, 2000.

RODRIGUES, V. Financiamento da educação e políticas públicas: o fundef e a política de descentralização. Cadernos Cedes, Campinas, v. 21, n. 55, nov. 2001.

SAVIANI, D. A nova lei da educação: trajetórias, limites e perspectivas. São Paulo: Autores Associados, 1997.

SILVA, F.C.R. A valorização dos profissionais das instituiçôes educacionais. Cadernos de Educação CNTE, Brasília, v. 1, n. 2, p. 5356, 1993. 